\title{
Mechanical behavior of materials with a compact hexagonal structure obtained by an advanced identification strategy of HCP material, AZ31B-H24
}

\author{
R. Harbaoui, O. Daghfas, A. Znaidi \\ Laboratory of Applied Mechanics and Engineering LR-MAI University Tunis El Manar-ENIT BP37-Le belvédère, 1002, Tunis \\ rym.barbaoui@gmail.com,daghfasolfa@yahoo.fr,amnaznaidi@laposte.tn
}

\section{Tuninetti}

Departament of Mechanical Engineering, Universidad de La Frontera, Francisco Salazar 01145, Temuco 4780000, Chile. victor.tuninetti@ufrontera.cl

\begin{abstract}
The use of magnesium alloys, in particular AZ31B-H24, represents an increasingly important aspect in the transport field, as well as in the aeronautical industry. In the forming processes of this material, the shapes of the product are obtained by plastic deformation. Therefore, it is important to know the properties of plastic behavior to optimize these shaping processes. The properties of this alloy are strongly influenced by its complex microstructure which can be modified by plastic deformation. For this purpose, in this work an identification strategy is established beginning with the elastoplastic orthotropic law based on the choice of an equivalent stress, a hardening law and a plastic potential. Thus, the anisotropic behavior of the magnesium sheet is modeled using CPB06 criterion with four hardening laws then later compared to Barlat91 criterion. Once the model is validated, it would therefore be useful to study the plastic behavior of AZ31B-H24 from an experimental database.
\end{abstract}

KEYWORDS. Magnesium; Model; Plastic deformation; Strategy; Anisotropy.

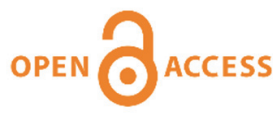

Citation: Harbaoui, R., Daghfas, O., Znaidi, V. Tuninetti A., Mechanical behavior of materials with a compact hexagonal structure obtained by an identification strategy, Case of study: Application on AZ31B-H2 Mg alloy, Frattura ed Integrità Strutturale, 53 (2020) 295-305.

Received: 07.02.2020

Accepted: 14.05.2020

Published: 01.07.2020

Copyright: (C) 2019 This is an open access article under the terms of the CC-BY 4.0, which permits unrestricted use, distribution, and reproduction in any medium, provided the original author and source are credited.

\section{INTRODUCTION}

he magnesium alloy has been praised by the greatest number of experts in materials engineering due to its low density, high thermal conductivity and rigidity, excellent mechanical and damping properties as well as excellent flowability [1-3]. In particular, the magnesium alloy material is a promising project in the transport sector.

Magnesium alloy sheets (AZ31B) have different mechanical responses than steel and aluminum sheets and have a highly anisotropic behavior due to their compacted hexagonal crystal structure (HCP) and strong basal crystallographic texture 
resulting from the rolling process $[4,5]$. It also results in a strong tension / compression asymmetry based on the test data of Kelley and Hosford [6]. More experience with different loading conditions is required for magnesium alloy sheets to fully understand their complex mechanical behavior. Jia and Bai [7] carried out a complete series of experiments on the plasticity and fracture of AZ31B-H24 magnesium under various multiaxial loading conditions.

The plasticity and fracture of magnesium is a significant challenge due to its closed HCP structure and its twinning deformation mechanism, which has not yet been properly detailed due to its complexity $[7,8]$.

To describe the plastic behavior of this material, it is necessary to specify the yield surface defined by an equivalent stress of a plasticity criterion and the hardening law.

In previous works, Amna et al $[9,10]$ have shown the ability of the Barlat criterion [11] to successfully simulate the plastic behavior in simple tensile test of pure aluminum [10], aluminum alloy 2024 [12] and aluminum alloy 7075 [13] and on the other hand in simple and cyclic shear tests of aluminum alloy 2024 [14].

On the other hand, Amna et al [9] have shown that this criterion is insufficient to model the plastic behavior of AZ31B Magnesium alloy sheets under multiaxial loading according to the Lankford coefficient. To remedy this insufficiency, Rym et al [15] used the Casazu criterion [16] which is dedicated to the compact hexagonal structure HCP to identify the plastic behavior of titanium alloy subjected to tensile tests.

In this work, the plastic behavior of the AZ31B-H24 alloy is modeled using an identification strategy that depends on a plastic Casazu criterion, an isotropic hardening law (Hollomon law, Voce law, swift law and ludwick law) and an evolution law. For this purpose, an experimental database [17] corresponds to various hardening curves for tensile and compression tests interpreted as homogeneous and their Lankford coefficients is used. Thereafter, by smoothing the experimental hardening curves in three loading directions relative to rolling direction, a selection is made in order to choose the most appropriate hardening law for the identification of the AZ31B-H24 behavior. Finally, our identification strategy with a Simplex method is validated from Lankford coefficients and it is used to conduct the evolution of the load surface for different tests.

\section{STUDIED MATERIAL}

I $\mathrm{n}$ this work, an AZ type magnesium alloy AZ31 has been studied. Its alloying elements are aluminum up to 3\%, zinc with $1 \%$ and finally $0.4 \%$ manganese [18].

The AZ31B-H24 magnesium alloy has a nominal composition (in wt \%) of $3 \% \mathrm{Al}$ and $1 \% \mathrm{Zn}$. The $\mathrm{H} 24$ condition refers to strain hardening and partially annealing (recrystallization without grain growth).

This material is treated as having an orthotropic plasticity in three directions: $\mathrm{RD}$ (rolling direction), TD (transverse direction) and ND (normal direction).

\begin{tabular}{ccccccccc}
\hline $\mathrm{Al}$ & $\mathrm{Zn}$ & $\mathrm{Mn}$ & $\mathrm{Cu}$ & $\mathrm{Ca}$ & $\mathrm{Ni}$ & $\mathrm{Fe}$ & $\mathrm{Mg}$ & $\mathrm{O}$ \\
$2.5-3.5$ & $0.7-1.3$ & $0.2 \min$ & $0.05 \max$ & $0.04 \max$ & $0.005 \max$ & $0.005 \max$ & balance & none \\
\hline
\end{tabular}

Table 1: Composition of AZ31B-H24 magnesium alloy (wt $\%$ )

\section{IDENTIFICATION MODEL}

I $\mathrm{n}$ this study, it is essential to use an identification strategy taking into account: the anisotropic behavior of the material and the SD "strength-differential" effect, the evolution law and the equivalent stress.

For the identification step, the following assumptions must be respected [9-15]:

- Identification by "small deformations",

- The used tests are considered as homogeneous tests,

- The elastic deformation are neglected; the behavior is considered as rigid plastic incompressible.

- The plasticity surface evolves homothetically (isotropic hardening)

- All the tests are carried out in the plane of the sheet resulting in a plane stress condition.

The performance criterion can be then written as follows:

$$
f\left(\bar{\sigma}^{D}, \alpha\right)=\sigma_{c}\left(\bar{\sigma}^{D}\right)-\sigma_{s}(\alpha)
$$


where $\bar{\sigma}^{D}$ is the deviator of the stress tensor of Cauchy (incompressible plasticity).

The hardening function $\sigma_{\mathrm{s}}(\alpha)$ plays the role of the thermodynamic function associated with the internal variable $\alpha$ $\sigma_{\mathrm{c}}\left(\bar{\sigma}^{D}\right)$ : equivalent stress of the plasticity criterion.

Function $\sigma_{c}\left(\bar{\sigma}^{D}\right)$ satisfies the following condition if a $>0$ :

$$
\sigma_{c}\left(a \bar{\sigma}^{D}\right)=a \sigma_{c}\left(\bar{\sigma}^{D}\right)
$$

The evolution of the surface load is represented in the spatial deviators of constraints, which are defined as follows:

$$
\overline{x_{1}}=\left|\sigma^{\mathrm{D}}\right| \cos \theta ; \overline{x_{2}}=\left|\sigma^{\mathrm{D}}\right| \sin \theta \cos 2 \psi ; \overline{x_{3}}=\left|\sigma^{\mathrm{D}}\right| \sin \theta \sin 2 \psi
$$

Using the special configuration of space deflectors, the general form of the equivalent plane stress is written as follows:

$$
\sigma_{\mathrm{c}}\left(\bar{\sigma}^{\mathrm{D}}\right)=\sigma_{\mathrm{c}}\left(\overline{x_{1}}, \overline{x_{2}},\left|\overline{x_{3}}\right|\right)=\left|\bar{\sigma}^{\mathrm{D}}\right| / \mathrm{f}(\theta, 2 \psi)
$$

Any type of criterion can be written in the following form:

$$
\mathrm{f}(\theta, 2 \psi)=\left|\bar{\sigma}^{\mathrm{D}}\right| / \sigma_{\mathrm{s}}(\alpha)
$$

The angle $\theta$ which defines the orientation of $\sigma^{\mathrm{D}}$ is presented in Table 2 and $\psi$ the off-axis angle.

\begin{tabular}{ccccc}
\hline Test & $\begin{array}{c}\text { Expansions } \\
\text { Equibiaxes (E.E) }\end{array}$ & $\begin{array}{c}\text { Simple Traction } \\
\text { (S.T) }\end{array}$ & $\begin{array}{c}\text { Large Traction } \\
\text { (L.T) }\end{array}$ & $\begin{array}{c}\text { Simple Shear } \\
\text { (S.S) }\end{array}$ \\
$\theta$ & 0 & $\pi / 3$ & $\pi / 6$ & $\pi / 2$ \\
\hline
\end{tabular}

Table 2: The angle $\theta$ respective to four tests [9-10].

First, to identify the hardening curve it is necessary to choose an appropriate analytical law. Second, an identification of the parameters that define the material anisotropy is also required.

For this step, the CPB06 criterion [19-23] is chosen to identify the behavior of AZ31B-H24 magnesium alloy.

The equivalent stress of $\mathrm{CPB} 06$ criterion is defined as follows:

$$
\sigma_{c}=\left(\sum_{i=1}^{3}\left(\left|q_{i}\right|-k q_{i}\right)^{m}\right)^{1 / m}
$$

where $\mathrm{q}_{1}, \mathrm{q}_{2}$ and $\mathrm{q}_{3}$ are the eigenvalues of the tensor $\mathbf{q}$

$$
\mathbf{q}=\mathbf{C}: \boldsymbol{\sigma}^{\mathrm{D}}
$$

$\mathbf{q}:$ modified stress deviator tensor

qi: the principal values of the tensor $\mathrm{q}$.

$\mathrm{m}$ : the degree of homogeneity also called form coefficient.

$\boldsymbol{\sigma}^{\mathrm{D}}$ : deviatoric stress tensor (incompressible plasticity)

C : 4th order tensor of the linear transformation. The components Cij are represented by (Voigt notation): 


$$
\mathrm{C}=\left[\begin{array}{cccccc}
C_{11} & C_{12} & C_{13} & 0 & 0 & 0 \\
C_{12} & C_{22} & C_{23} & 0 & 0 & 0 \\
C_{13} & C_{23} & C_{33} & 0 & 0 & 0 \\
0 & 0 & 0 & C_{44} & 0 & 0 \\
0 & 0 & 0 & 0 & C_{55} & 0 \\
0 & 0 & 0 & 0 & 0 & C_{66}
\end{array}\right]
$$

The parameter $\mathrm{k}$ may be determined from experimental values of $\sigma \mathrm{tr}$ and $\sigma \mathrm{cp}$ :

$$
k=\frac{1-b\left(\sigma_{t r} / \sigma_{\phi p}\right)^{\frac{1}{m}}}{1+h\left(\sigma_{t r} / \sigma_{\phi p}\right)^{\frac{1}{m}}}, h\left(\sigma_{t r} / \sigma_{\phi p}\right)=\left[\frac{2^{m}-2\left(\sigma_{t r} / \sigma_{\phi p}\right)^{\prime \prime}}{\left(2 \sigma_{t r} / \sigma_{t p}\right)^{m}-2}\right]
$$

$\mathrm{k}$ : the parameter of the material, the ratio between the uniaxial yield in traction $\sigma \mathrm{tr}$ and the uniaxial yield in compression $\sigma \mathrm{cp}$ allowing the description of the differential effect of resistance

$h:$ is a variable that defines the history of the material

To ensure the convexity of the plasticity surface, we fix $m \geq 1,-1 \leq k \leq 1$

The hardening functions $\sigma_{s}\left(\alpha=\varepsilon^{p}\right)$ used are:

Hollomon law [24] $\left(\mathrm{Hol} \psi^{\circ}\right)$ :

$$
\left.\sigma_{s}\left(\varepsilon^{p}\right)=K\left(\varepsilon^{p}\right)^{n}\right)
$$

Voce law [25] (Voce $\left.\psi^{\circ}\right)$ :

$$
\sigma_{s}\left(\varepsilon^{p}\right)=\sigma_{y}\left(1-\alpha \exp \left(\beta \varepsilon^{p}\right)\right)
$$

Swift law [26] $\left(\right.$ Swift $\left.\psi^{\circ}\right)$ :

$$
\sigma_{s}\left(\varepsilon^{p}\right)=K\left(\varepsilon_{0}+\varepsilon^{p}\right)^{n}
$$

Ludwick law [27] $\left(\right.$ Ludwick $\left.\psi^{\circ}\right)$ :

$$
\sigma_{s}\left(\varepsilon^{p}\right)=\sigma_{0}+K\left(\varepsilon^{p}\right)^{n}
$$

The parameters $\mathrm{K}$ and $\mathrm{n}$ for Hollomon's law

The parameters $\sigma_{\mathrm{y}}, \alpha$ and $\beta$ for the Voce's law

The parameters $\varepsilon_{0}, \mathrm{~K}$ and $\mathrm{n}$ for Swift's law

The parameters $\sigma_{0}, \mathrm{~K}$ and $\mathrm{n}$ for Ludwick's law

\section{RESULTS AND DISCUSSION}

\section{Experimental results}

$\mathrm{F}$ igs. 1 and 2 respectively represent the uniaxial tensile and compression hardening curves for three different orientations: $\mathrm{RD}$ (rolling direction), TD (transverse direction) and ND (normal direction).

By analyzing the curves in Figure 1 and Figure 2, we notice an anisotropy translated by the difference between the three directions. On the other hand, this anisotropy in normal direction (ND) for the two tests is different from that of the other directions which translates the phenomenon of asymmetry between traction and compression encountered in magnesium alloys.

The yield and flow stresses for ND compression curve followed similar characteristics as in-plane tension at RD and TD directions. The yield stresses for RD are lower than those for TD and ND. 


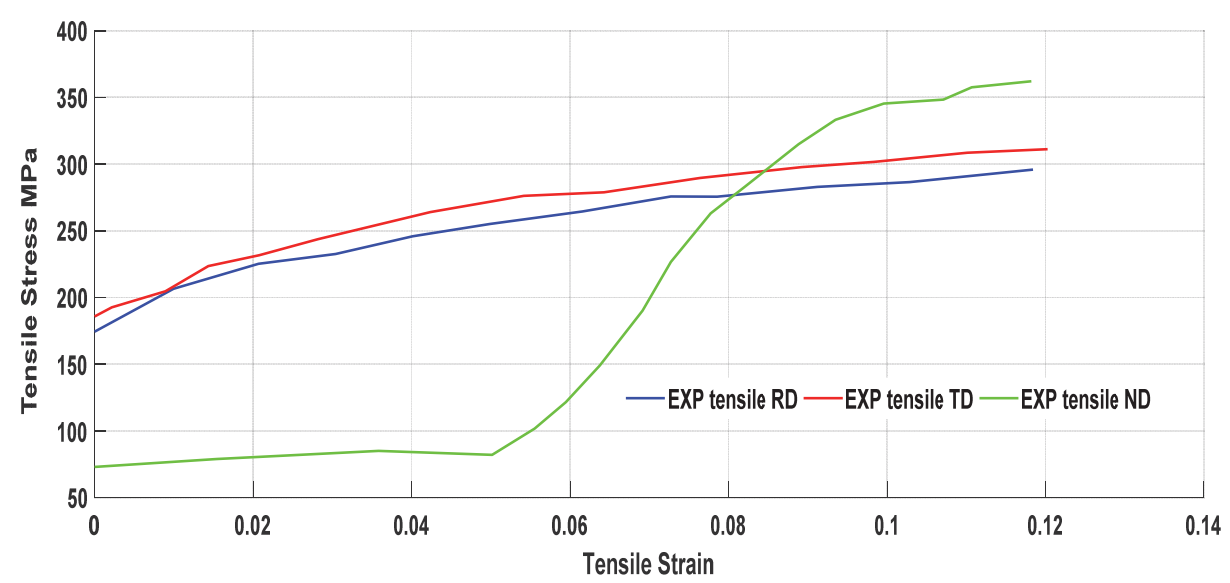

Figure 1: Hardening Curves of uniaxial tensile [17].

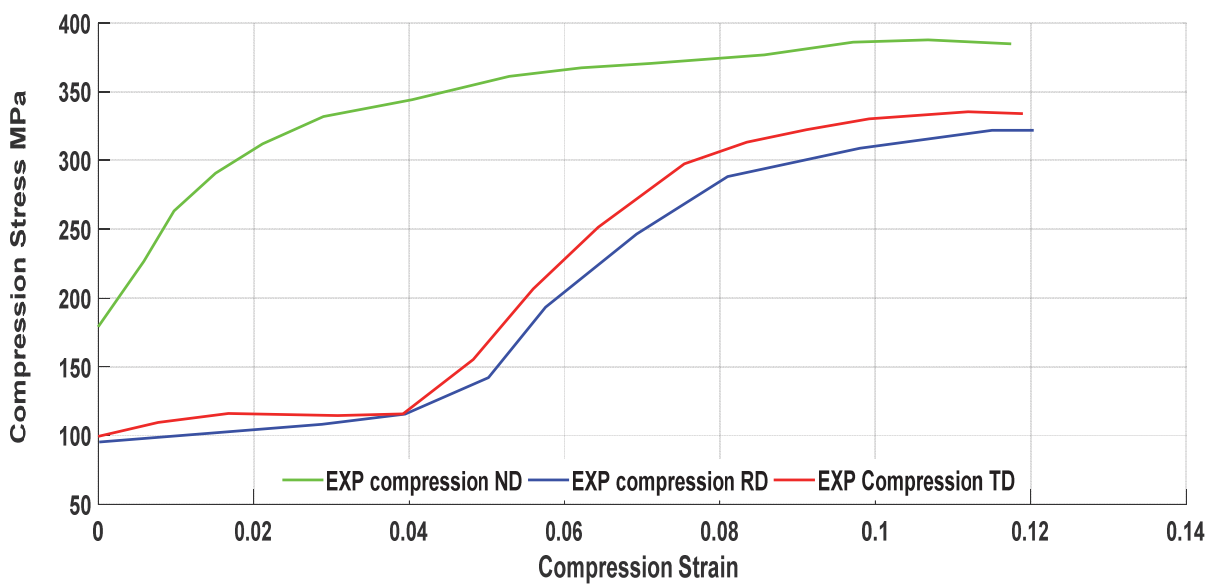

Figure 2: hardening curves of uniaxial compression [17].

\begin{tabular}{cc}
\hline$\left(^{\circ}\right)$ & Lankford coefficients \\
0 & 1.47 \\
45 & 2.77 \\
90 & 3.89 \\
\hline
\end{tabular}

Table 3: Experimental Lankford coefficients.

Numerical results:

Identification of the hardening parameters

For the identification procedure, we will use the CPB06 model [9] while respecting the assumptions cited above.

This step consists of choosing the coefficients of the model while minimizing the squared difference between the theoretical and experimental results.

The hardening function $\sigma_{\mathrm{s}}(\alpha)$ is identified from the tensile hardening curves in the TD and RD directions for the tensile test (Figure 1) and of the experimental compression test (Figure 2) in the ND direction. In this case, four handening laws are used: Hollomon's law, Voce's law, Swift's law and Ludwick's law to best describe the function $\sigma \mathrm{s}(\alpha)(9)-(12)$.

The experimental results found are the first and only source of data for the implementation of this identification strategy. The identification results are shown in Tables 4 and 5.

Table4, table 5 and table 6 present the identified parameters of the hardening laws for tensile tests in rolling direction, in transverse direction and for compression test in normal direction, respectively. 


\begin{tabular}{cl|cc|cc|cc}
\hline \multicolumn{2}{c|}{ Hollomon } & \multicolumn{2}{c|}{ Swift } & \multicolumn{2}{c}{ Ludwick } & \multicolumn{2}{c}{ Voce } \\
Err & 0.0205 & Err & 0.0116 & Err & 0.0124 & Err & 0.0372 \\
$\mathrm{~K}$ & 402.605 & $\mathrm{~K}$ & 447.0761 & $\sigma_{0}$ & 150.6813 & $\sigma_{\mathrm{y}}$ & 1440.8 \\
$\mathrm{n}$ & 0.1496 & $\varepsilon_{0}$ & 0.0116 & $\mathrm{~K}$ & 337.5205 & $\alpha$ & 0.9 \\
& & $\mathrm{n}$ & 0.2015 & $\mathrm{n}$ & 0.3925 & $\beta$ & -0.7 \\
\hline
\end{tabular}

Table 4: Identified parameters of the hardening laws for the tensile test (RD).

\begin{tabular}{ll|lc|lc|cc}
\hline \multicolumn{2}{c|}{ Hollomon } & \multicolumn{2}{c|}{ Swift } & \multicolumn{2}{c}{ Ludwick } & \multicolumn{2}{c}{ Voce } \\
Err & 0.0123 & Err & 0.0118 & Err & 0.0118 & Err & 0.0517 \\
$\mathrm{~K}$ & 439.1366 & $\mathrm{~K}$ & 445.9781 & $\sigma_{0}$ & 51.4125 & $\sigma_{\mathrm{y}}$ & 610.305 \\
$\mathrm{n}$ & 0.1621 & $\varepsilon_{0}$ & 0.0013 & $\mathrm{~K}$ & 401.2347 & $\alpha$ & 0.662 \\
& & $\mathrm{n}$ & 0.1693 & $\mathrm{n}$ & 0.2032 & $\beta$ & -2.8943 \\
\hline
\end{tabular}

Table 5: Identified parameters of the hardening laws for the tensile test (TD).

\begin{tabular}{ll|lc|lc|cc}
\hline \multicolumn{2}{c|}{ Hollomon } & \multicolumn{2}{c|}{ Swift } & \multicolumn{2}{c}{ Ludwick } & \multicolumn{2}{c}{ Voce } \\
Err & 0.0194 & Err & 0.0076 & Err & 0.0167 & Err & 0.038 \\
$\mathrm{~K}$ & 540.4411 & $\mathrm{~K}$ & 490.1859 & $\sigma_{0}$ & -422.981 & $\sigma \mathrm{y}$ & 502.9209 \\
$\mathrm{n}$ & 0.1427 & $\varepsilon_{0}$ & -0.0099 & $\mathrm{~K}$ & 940.3702 & $\alpha$ & 0.4453 \\
& & $\mathrm{n}$ & 0.0995 & $\mathrm{n}$ & 0.064 & $\beta$ & -7.1496 \\
\hline
\end{tabular}

Table 6: Identified parameters of the hardening laws for the compression test (ND).

\section{Identification of the bardening curves:}

In Figure 3,4 and 5, the experimental hardening curves (EXP) and the identified curves using the four hardening laws are represented for three tests.

The identification consists of finding the hardening function $\sigma s(\alpha)$, applying the least squares fitting between the theoretical and the experimental results using the simplex algorithm. Thereafter, a comparison between the four hardening laws will be carried out in order to show the most appropriate law for the identification of tensile and compressive hardening curves in plastic deformation.

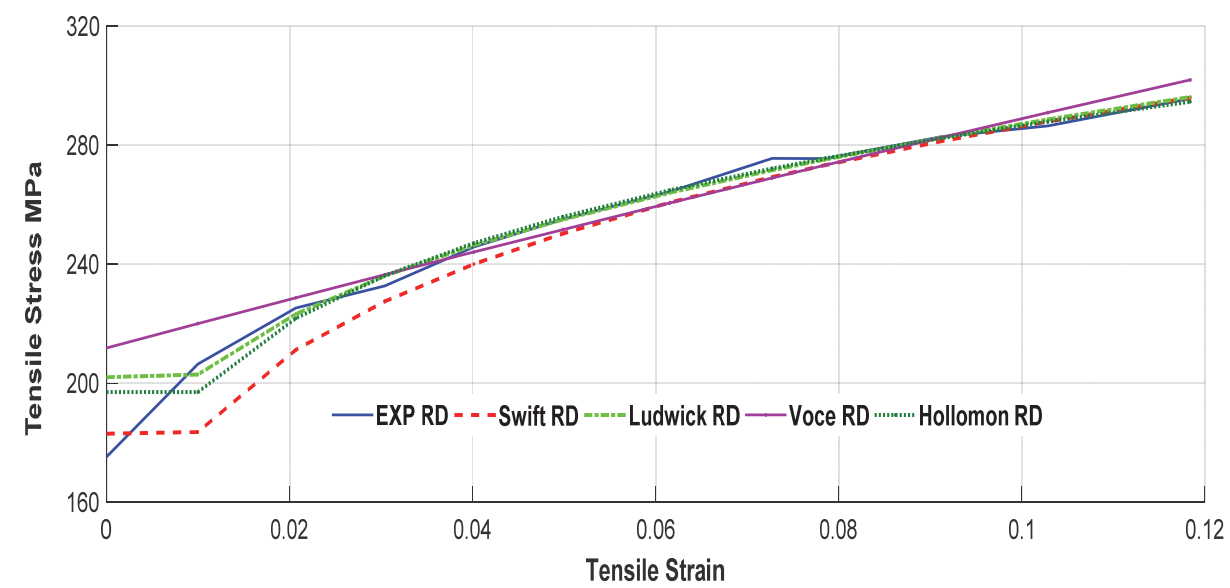

Figure 3: Identification of the tensile curve for $\mathrm{RD}$ with different hardening laws 


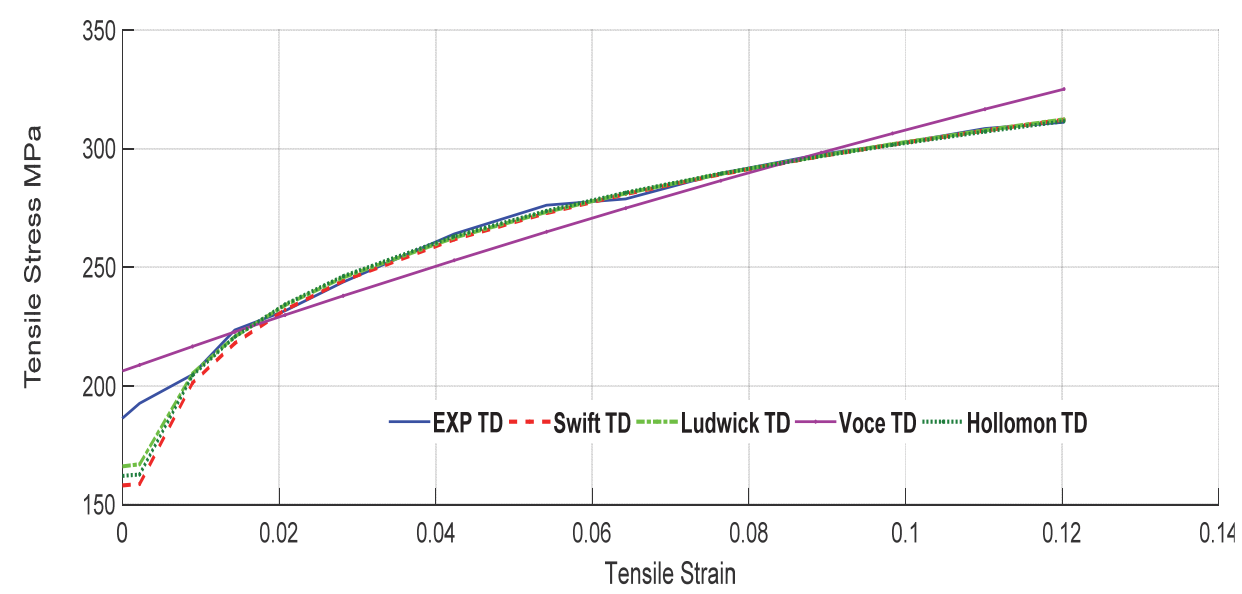

Figure 4: Identification of the tensile curve for TD with different hardening laws

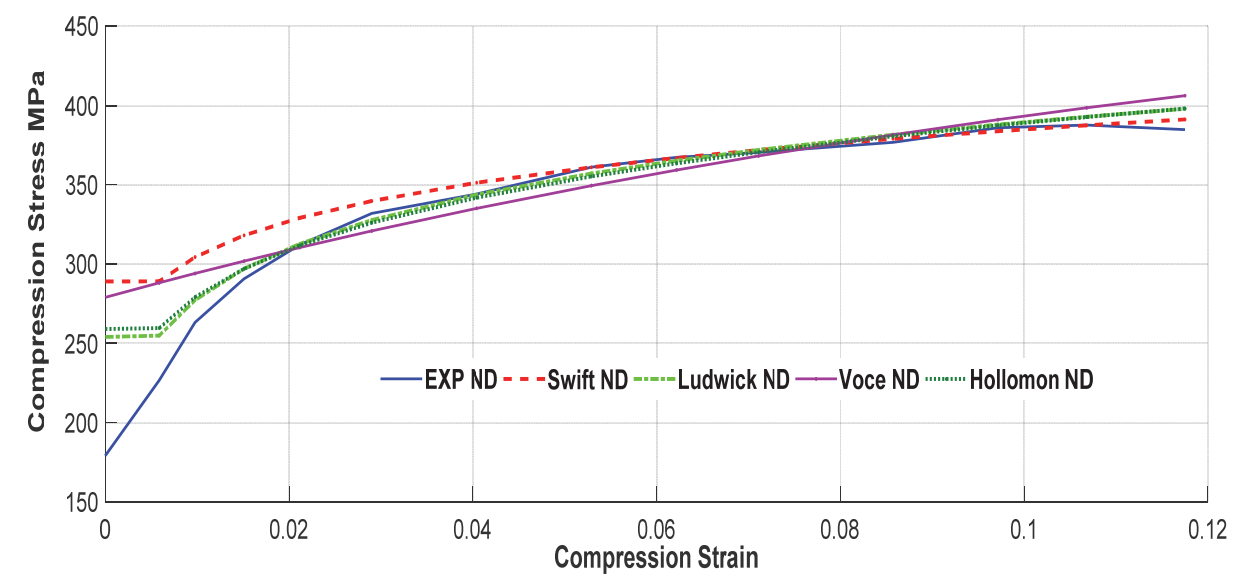

Figure 5: Identification of the compression curve for ND with different hardening laws

The identification is made in the area of plastic deformation where the elastic deformation is neglected (as it is indicated above in the hypothesis).

It is clearly seen that the Swift and Voce laws are a little far from identifying AZ31B in uniaxial deformation. Indeed, the Ludwick and Hollomon laws describe the hardening curves better than those of Voce for all the loading directions. On the other hand, Ludwick and Hollomon laws give very similar results for the TD and RD directions for the tensile test compared to the rolling direction especially at the area of the plastic deformation domain.

We can therefore conclude that Ludwick's law is sufficient to model the plastic behavior of the magnesium alloy in the two cases of monotonic loading: simple tensile and simple compression.

In conclusion, the isotropic hardening Ludwick's law is chosen in continuation of this work to identify the anisotropic behavior of this alloy.

Validation:

After proving in previous work [9] and [10] that $\mathrm{n}$ remains the same for different tests, table 7 and 8 present the identified parameters where $\mathrm{n}$ is fixed for $\psi=0^{\circ}$.

We will therefore choose ' $n$ ' relating to the tensile test carried out in the rolling direction in addition to that it is the most simple and easy test to perform.

By convention, we choose $\mathrm{n}$ for tensile test in the rolling direction as a reference. For $\mathrm{n}=0.3925$, we present different values of $\mathrm{K}$ and $\sigma_{0}$ (Table 7).

\begin{tabular}{ccc}
\hline & Ludwick00 & Ludwick TD \\
Error & 0.0124 & 0.0192 \\
$\sigma_{0}$ & 150.6813 & 148.4634 \\
$\mathrm{~K}$ & 337.5205 & 384.4332 \\
\hline
\end{tabular}

Table 7: Hardening parameters for Ludwick law for fixed $n=0.3925$ 


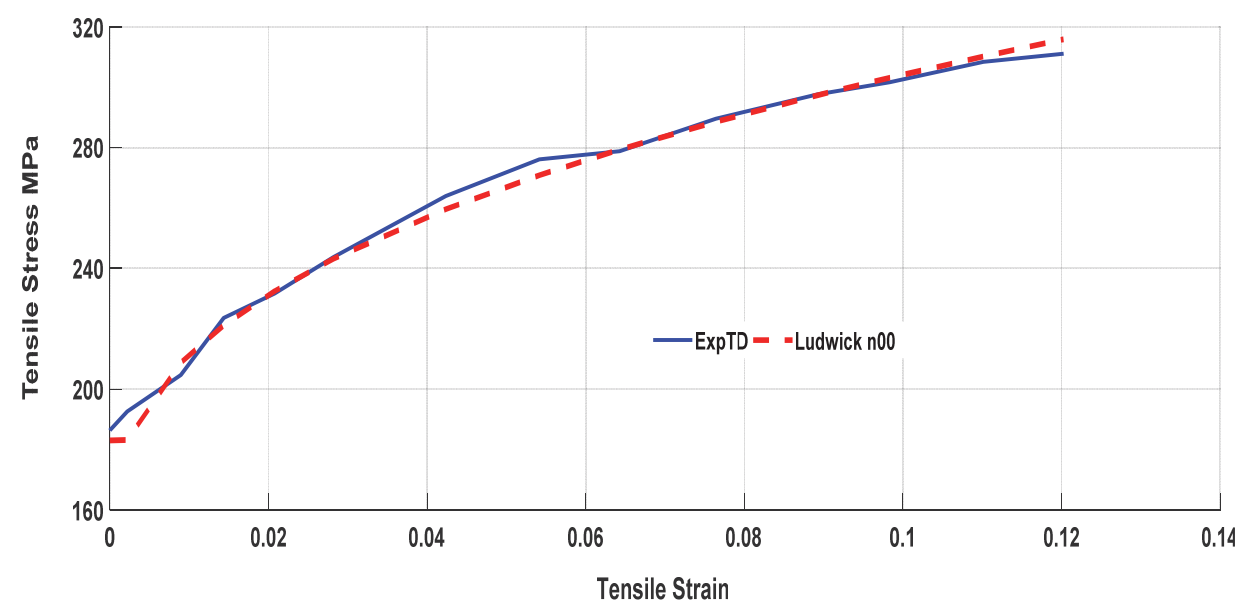

Figure 6: Identified tensile hardening curve with Ludwick law for TD

Validation of the compression curve in the normal direction (ND) using the values identified by fixing the coefficient $\mathrm{n}$ of the tensile test:

\begin{tabular}{ccc}
\hline & Ludwick ND & Ludwick $\mathrm{n}=\mathrm{n} 00$ \\
Error & 0.0167 & 0.0284 \\
$\sigma_{0}$ & -422.981 & 217.7096 \\
$\mathrm{~K}$ & 940.3702 & 428.4957 \\
\hline
\end{tabular}

Table 8: Hardening parameters for Ludwick law for fixed $n=0.3925$

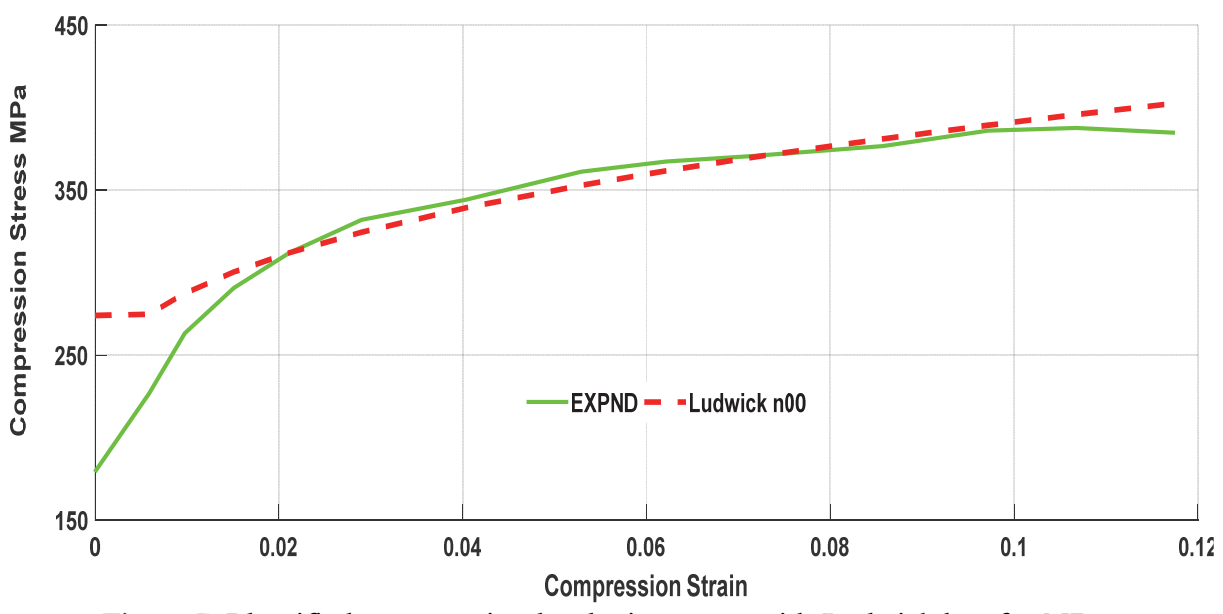

Figure 7: Identified compression hardening curve with Ludwick law for ND

Our identification strategy allows us to identify the experimental hardening curve along the two directions TD and ND using the identified parameters of the ludwick law according to the rolling direction RD.

Identification of the anisotropic coefficients of the plasticity model:

The second identification step consists in identifying the anisotropic parameters describing the CPB06 criterion using the identified hardening parameters of the Ludwick law that is chosen previously. While respecting the initial hypotheses identifying our meta-model, we identify the anisotropy coefficients and the material parameter $\mathrm{k}$ which will be represented in the table 9 .

Using the non quadratic $\mathrm{CPB} 06$ criterion, the previous identification is followed by an identification of the anisotropy coefficients of the forth order tensor $\mathbf{C}$ and the material parameter $\mathrm{k}$, for a fixed degree of homogeneity (shape coefficient $\mathrm{m}=2) \mathrm{C}_{44}=\mathrm{C}_{55}=\mathrm{C}_{66}=1$. 


\begin{tabular}{llllllll}
\hline $\mathrm{k}$ & $\mathrm{C}_{11}$ & $\mathrm{C}_{12}$ & $\mathrm{C}_{13}$ & $\mathrm{C}_{22}$ & $\mathrm{C}_{23}$ & $\mathrm{C}_{33}$ & Error \\
-0.02 & 1 & 0.2283 & 0.3197 & -1.3154 & -2.0016 & -2.6882 & $1.1177 \mathrm{e}-07$ \\
-0.3 & 1 & 0.1014 & 0.0521 & -0.9734 & 0.4437 & 4.8881 & $1.1394 \mathrm{e}-10$ \\
\hline
\end{tabular}

Table 9: Identification of the anisotropy coefficients for a $=2$ by CPB06.

\section{Material behavior study}

- Validation using the Lankford coefficient

Based on the identified anisotropic parameters and the experimental Lankford coefficients, the development of the Lankford coefficients based on off-axis angles $\psi$ can be represented.

In Figure 8, the experimental Lankford coefficient (EXP) and the curves identified by our behavior model using Cazacu criterion and the curves identified from model using the barlat criterion (Barlat1991) are represented.

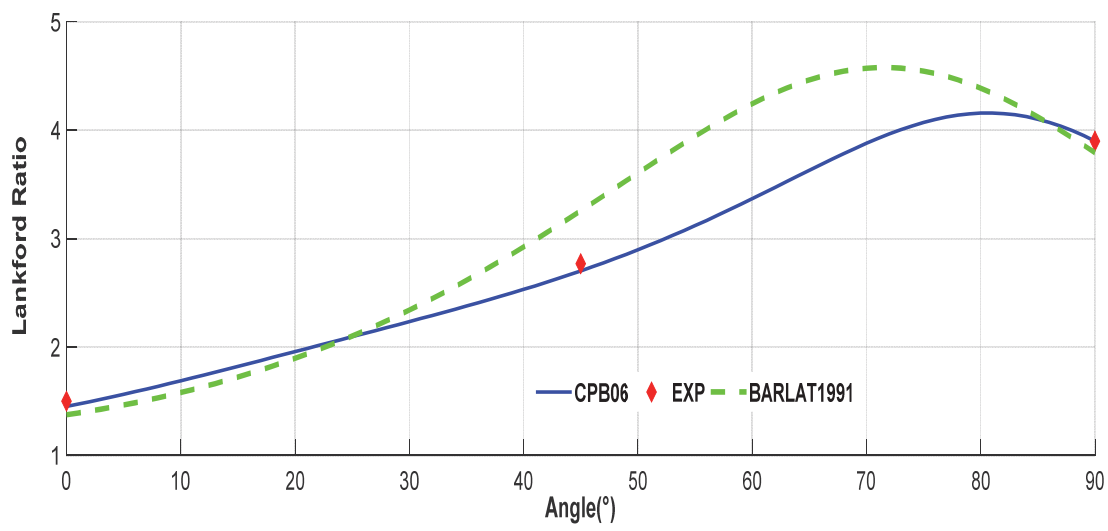

Figure 8: Evolution of the experimental lankford coefficient compared to those of CPB06 model and Barlat91 model.

Figure 8 show a good agreement between the identified results using our identification strategy and the experimental results relating to the Lankford coefficients.

We notice that there is an adjustment (a good agreement) between the experimental results and those obtained from the model using the $\mathrm{CPB} 06$ criterion.

However, the identification using the Barlat91 criterion is not validated by the Lankford coefficient.

This improvement is exclusive to structure of studied material: the Barlat criterion is dedicated to face-centered cubic structure such as aluminum alloys [9-10,12]. On the other hand, the Cazacu criterion is developed to model the material behavior with a compact hexagonal structure such as magnesium alloys and titanium alloys $[9,15]$.

\section{- Load surface}

After the identification of the model, the evolution of the load surface can be studied when the material is subjected to four solicitations. Using the identified anisotropy parameters and based on equations (3)-(5) and table 2, the evolution of the load surface under different stresses (EE, WT, SS, ST) is presented in Figure 9.

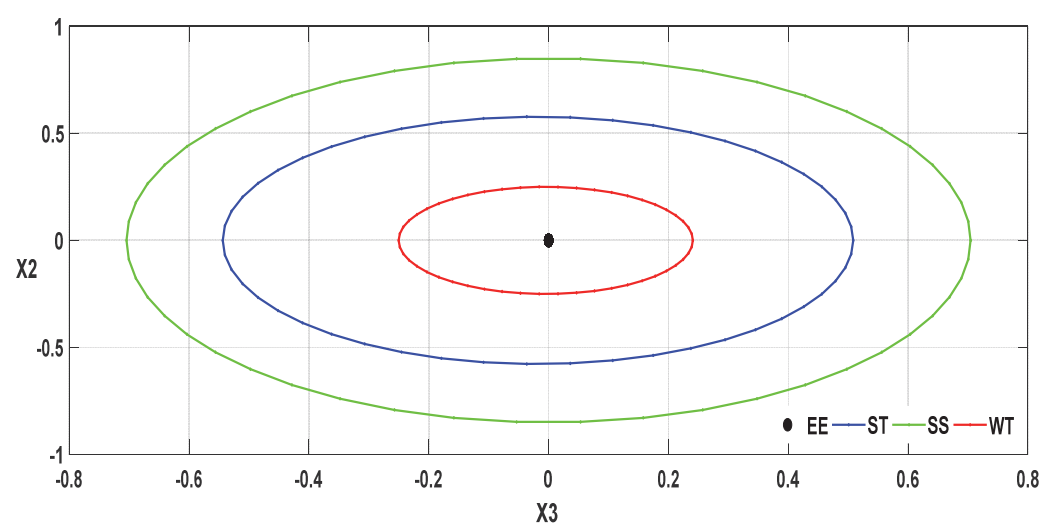

Figure 9: Evolution of the load surface to several tests and solicitations. 
This allows to represent the load surface $\mathrm{f}(\theta, 2 \psi)$ in space $\left(\bar{x}_{1}, \bar{x}_{2}, \bar{x}_{3}\right)$.

Using the base of constraint deviators:

$$
X 2=\frac{\bar{x}_{2}}{\left|\sigma^{D}\right|} \quad X 3=\frac{\bar{x}_{3}}{\left|\sigma^{D}\right|}
$$

For the load surface, it is clear that the material is more resistant in simple shear than in uniaxial traction.

\section{CONCLUSION}

I $\mathrm{n}$ this work, based on an experimental database, we have developed an identification strategy centered on the parameters of plasticity, the hardening law and lankford coefficients in order to raise previously unresolved identification issues.

After construction of the model, an identification methodology was presented from the monotonic tensile and compression hardening curves. The first step consists in identifying the tensile and compression curves by the different hardening laws in order to choose the most adequate law to best describes the material behavior, while comparing it with the experimental curves.

The second step of the strategy consists in identifying the anisotropy parameters of the material studied by the CPB06 criterion using the Ludwick law as a hardening law.

The used criterion takes into account the strong anisotropy as well as the SD effect "strength differential" translated by the traction-compression asymmetry.

A validation by comparing the model to the experimental database was carried out; the validation of the model is established using the experimental values of the lankford coefficient.

A comparison between the CPB06 and Barlat criterions were carried out. It is found that the anisotropy evolves in the same way for an identification strategy using the $\mathrm{CPB} 06$ criterion as well as the Barlat criterion. On the other hand, the validation by the Lankford coefficient is well respected by the CPB06 criterion.

Thus, from the identification results of the anisotropy parameters and the Lankford coefficients, it was possible to verify that the identification using the CPB06 criterion gives clearly more efficient results compared to other criteria, in particular Barlat91.

\section{REFERENCES}

[1] Yueqian, J. (2011). Study on anisotropic plasticity and fracture of lightweight metal sheets, M.S. University of Central Florida, 2013 B.S. Northwestern Polytechnical University, China

[2] Manuel, M., Hector, L.G. , Verma, R., Tong, W. (2006). Microstructural effects of AZ31 magnesium alloy on its tensile deformation and failure behaviors, Materials Science and Engineering, A418, pp. 341-356.

[3] Roberts C. Sheldon (1960). Magnesium and Its Alloys, New York, NY: John Wiley and Sons

[4] Yuqian, W., Duke, C., Yanyao, J. (2019). An experimental study of anisotropic fatigue behavior of rolled AZ31B magnesium alloy, DOI: 10.1016/j.matdes.2019.108266.

[5] Graff, S., Brocks, W., Steglich, D. (2007). Yielding of magnesium: from single crystal to polycrystalline aggregates , Int. J. Plast., 23 (12), pp. 1957-1978

[6] Kelly, E.W., Hosford, W.F.(1968). Plane-strain compression of magnesium and magnesium alloy crystals. Trans.Metall. Soc. AIME 242, 5-13.

[7] Yueqian, J, Yuanli B. (2016). Experimental study on the mechanical properties of AZ31B-H24 magnesium alloy sheets under various loading conditions, International Journal of Fracture, 197, pp. 25-48.

[8] Lou, X.Y., M. Li, Boger, R.K., Agnew, S.R., Wagoner, R.H. (2007). Hardening evolution of AZ31B Mg sheet Int. J. Plast., 23 (1), pp. 44-86.

[9] Znaidi, A., Daghfas, O., Guellouz, S., Nasri, R. (2016). Theorical study on mechanical properties of AZ31B Magnesium alloy Sheets under multiaxial loading, Frattura ed Integrità Strutturale, 38, 135-140; DOI: 10.3221/IGF-ESIS.38.18

[10] Znaidi, A., Daghfas, O., Gahbiche, A., et al. (2016). Identification strategy of anisotropic behavior laws: application to thin sheets of A5. J. Theor. Appl. Mech, 54, pp. 1147-1156. DOI:10.15632/jtam-pl.54.4.1147. 
[11] Barlat, F., Lege, D.J., Brem, J.C. (1991). A six-component yield function for anisotropic materials, International. Journal of Plasticity, 7, pp. 693-712.

[12] Daghfas, O., Znaidi, A. , Nasri, R. (2019). Plastic Behavior Laws of Aluminum Aerospace Alloys: Experimental and Numerical Study. Journal of the Chinese Society of Mechanical Engineers, 40(5), pp. 523-532.

[13] Daghfas, O., Znaidi, A., Ben Mohamed, A., et al (2017). Experimental and numerical study on mechanical properties of aluminum alloy under uniaxial tensile test. Frattura ed Integrità Strutturale 11(39), pp. 263-273. DOI: $10.3221 /$ IGF-ESIS.39.24.

[14] Daghfas, O., Znaidi , A., Gahbiche, A. , Nasri, R. (2019). Identification of the anisotropic behavior of an aluminum alloy subjected to simple and cyclic shear tests. Proc IMechE Part C: J Mechanical Engineering Science 2019, 233(3) pp. 911-927. DOI: $10.1177 / 0954406218762947$.

[15] Harbaoui, R., Znaidi, A., Nasri, R. (2017). Modeling of titanium alloys by an identification strategy: Biomechanical application. pp. 73-86. DOI:https://doi.org/10.3166/rcma.2017.00005.

[16] Cazacu, O., Plunkett, B., Barlat, F. (2008). Orthotropic yield criterion description of anisotropy in tension and compression of sheet metals. Int. J. Plasticity, 24, pp. 847-866.

[17] Nitin ,C., Ricardo, A. L. , Benoit, R. B. , Oana, C. , Barlat, F. (2015). Combined effects of anisotropy and tensioncompression asymmetry on the torsional response of AZ31 Mg, International Journal of Solids and Structures, 58, pp. 190-200.

[18] Housh, S., Mikucki, B., Stevenson, A. (1990). Properties of Magnesium Alloys in Metals Handbook, 2(10), "Properties and Selection: Nonferrous Alloys and Special Purpose Materials". ASM International, MateriaIs Park.

[19] Cazacu, O., Ionescu, I. R. , Yoon, J. W. (2009). Orthotropic strain rate potential for the description of anisotropy in tension and compression of metals. Int. J. Plasticity.

[20] Yueqian, J., Xiang, L., Yuanli, B. (2012). Theorical Study On Mechanical Properties of AZ31B Magnesium Alloy Sheets Under Multiaxial Loading. J Automotive Safety and Energy, 4.

[21] Cazacu, O., Plunkett, B., Barlat, F. (2006) Orthotropic yield criterion for hexagonal closed packed metals. International Journal of Plasticity, 22, pp. 1171-1194.

[22] Cazacu, O. (2015). Application of the VPSC Model to the Description of the Stress-Strain Response and Texture Evolution in AZ31, Journal of Engineering Materials and Technology.

[23] Baudard, B.R., Cazacu, O. (2016). Plasticity-damage coupling in anisotropic titanium and validation by XCMT, XXIV ICTAM, Montreal, Canada.

[24] Hollomon, J.H. (1945). Tensile deformation. Trans AIME. 162, pp. 268-290.

[25] Voce, E. (1948). The relationship between stress and strain for homogeneous deformations. J Inst Metals; 74, pp. 537562.

[26] Swift, H.W. (1952). Plastic instability under plane stress, Journal of the Mechanics and Physics of Solids. 1(1), pp. 1-18.

[27] Ludwik, P. (1909). Applied Mechanik : Elemente der technologischen mechanik. Springer Verlag, Berlin. 